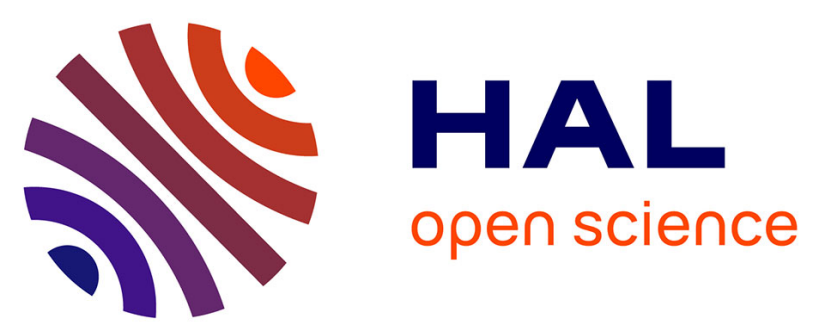

\title{
DISCREPANCIES AND ANALOGIES IN ARTIFICIAL INTELLIGENCE AND ENGINEERING DESIGN APPROACHES IN ADDRESSING THE COLLABORATIVE DECISION-MAKING
}

\author{
Marija Jankovic, Pascale Zaraté
}

\section{To cite this version:}

Marija Jankovic, Pascale Zaraté. DISCREPANCIES AND ANALOGIES IN ARTIFICIAL INTELLIGENCE AND ENGINEERING DESIGN APPROACHES IN ADDRESSING THE COLLABORATIVE DECISION-MAKING. International Journal of Decision Support System Technology, 2011, 3 (2), pp.1-14. hal-00823995

\section{HAL Id: hal-00823995 https://hal.science/hal-00823995}

Submitted on 20 May 2013

HAL is a multi-disciplinary open access archive for the deposit and dissemination of scientific research documents, whether they are published or not. The documents may come from teaching and research institutions in France or abroad, or from public or private research centers.
L'archive ouverte pluridisciplinaire HAL, est destinée au dépôt et à la diffusion de documents scientifiques de niveau recherche, publiés ou non, émanant des établissements d'enseignement et de recherche français ou étrangers, des laboratoires publics ou privés. 


\title{
DISCREPANCIES AND ANALOGIES IN ARTIFICIAL INTELLIGENCE AND ENGINEERING DESIGN APPROACHES IN ADDRESSING THE COLLABORATIVE DECISION-MAKING
}

\author{
Marija Jankovic* - Pascale Zaraté** \\ * Ecole Centrale Paris \\ Grande Voie des Vignes \\ 92295 Chatenay-Malabry \\ marija.jankovic@ecp.fr \\ ** Université de Toulouse \\ INPT - ENSIACET - IRIT \\ 118 route de Narbaonne \\ 31062 Toulouse Cedex 9 \\ Pascale.Zarate@irit.fr
}

\begin{abstract}
One of the trends in the decision-making field in the past 20 years have been the migration from individual decision-making to collective one. We can state several changes of working conditions that influenced this trend: geographical dispersion due to the business internationalisation, concurrent work in order to satisfy time delays, facilitation of the information sharing induced by the development of local area networks (LAN) and internet. In this study we address the discrepancies and analogies in addressing the collaborative decision making in two scientific fields: artificial intelligence and engineering design. These two fields have different considerations and approaches in view to the decision-making support. In this paper, we expose a comparative study concerning two research studies, both decision support oriented: the first one concerns the collaborative decision-making in early design stages in vehicle development projects (Jankovic, Bocquet, Stal Le Cardinal, \& Bavoux, 2006) and the second one concerns the development of an architecture of a Cooperative decision Support Systems (CDSS) (Zaraté, 2005).
\end{abstract}

KEYWORDS: DSS, Cooperative DSS, Collaborative Decision-making, New Product and Process Development, Engineering design

\section{INTRODUCTION}

One of the trends in the decision-making field in the past 20 years have been the migration from individual decision-making to collective one (Shim et al., 2002). We can state several changes of working conditions that influenced this trend: geographical dispersion due to the business internationalisation, concurrent work in order to satisfy time delays, facilitation of the information sharing induced by the development of local area networks (LAN) and the internet.

Several research fields address the issues of group, cooperative and collaborative decisionmaking. In this study we particularly focus on two fields: artificial intelligence and engineering design. These two fields have different definitions concerning these types of 
decision-making and different approaches when addressing the problem of decision support. Therefore, we explore two research studies in order to make a comparative study of results and discuss further implication leading towards a more integrated approach. The first study concerns the collaborative decision-making in early design stages in vehicle development (Jankovic, Bocquet, Stal Le Cardinal, \& Bavoux, 2006). The main objectives of this study are: 1) identifying key parameters for collaborative decision making in order to support the design team and 2) proposing an adequate support tool integrated into project management tools, already existing. The second study concerns a Cooperative Decision Support Framework (CDSF) (Zaraté, 2005). This framework is under development at the IRIT laboratory and was partially used in industrial context (i.e. Airbus).

Main objective of this research work is to identify the discrepancies and analogies in addressing the decision-support concerning the two proposed research studies. Therefore, the authors try to address: 1) key parameters or data that are indentified and supported by both approaches and 2) differentiating elements with the aim of discussing potential further developments concerning decision-support tools. Identifying these discrepancies and analogies might be relevant in order to propose more integrated approaches and identify the difference in decision-making processes in different domains.

Therefore, to address these issues we propose to discuss the definitions and approaches concerning cooperative and collaborative decision making, mostly in the field of artificial intelligence and engineering design. In the second part of this paper, we expose the characteristics and specificities of collaborative decision-making in early design stages, i.e. conceptual design. The third part of the paper gives an overview of the proposed cooperative decision support framework. At the very end of this paper, we propose to discuss these two approaches and conclusions concerning the differentiating elements in these two studies.

\section{Literature REVIEW}

The necessity of using the information technologies for supporting business processes and decision making has been growing in the past two or three decades (Kim, Godbole, Huang, Panchadhar, \& W., 2004). Moreover, the development of the world wide web has been accelerating these process, introducing new application. For example, decision-support tools integrating different consensus management techniques to develop a solution (Kim, Godbole, Huang, Panchadhar, \& W., 2004). This development of information technologies and the change $\mathrm{i}$, working organisations have also been raising interest for supporting group decision-making and developing cooperative decision support systems (CSDS) (Zaraté, 2005).

Nevertheless, the research literature does not give a uniform definition and characterization of different types of decision making, especially when it comes to cooperative and collaborative decision making. We can observe that difference between the artificial intelligence (Al) field addressing the decision-support systems and engineering design. In Al, the most integrated decision-making, in view to decision-making objectives sharing, is considered to be cooperative decision making where different actors have the same objectives and might be geographically distributed (Zaraté, 2005). In engineering design, due 
to the system engineering objectives, the most integrated decision-making process is considered to be the collaborative decision-making where decision makers do have common global objectives but also have objectives in the decision-making process that concern their own design domain (Jankovic, 2006). This is due to the complexity of design processes and the necessity to perform the cascading of design objectives and therefore the decisionmaking objectives.

Some of the work in Al fields when speaking of collaborative decision-making considers distributed asynchronous decision-making (Aldunate, Pena-Mora, \& Robinson, 2005; Chim, Anumba, \& Carrillo, 2004; Cil, Alpturk, \& Yazgan, 2005), which is often similar to the definition given for cooperative decision-making. Some research studies refer to it as multiactor decision-making where actors have different goals (Karacapilidis \& Papadias, 2001; Panzarasa, Jennings, \& Norman, 2002).

Panzarasa and Jennings (Panzarasa, Jennings, \& Norman, 2002) consider collaborative decision-making as a multi-agent socio-cognitive process. Thus they incorporate beliefs, goals, desires, intentions, and preferences in what they call mental modelling. The authors also adopt a prescriptive approach in order to give a set of possible actions at every step of collaborative decision-making. The model is developed using social mental shaping, the process by which the mere social nature of agents may impact upon their mental states and motivate their behaviour. Their collaborative decision-making model consists of four phases: the practical starting-point, group generation, social practical reasoning, and negotiation.

Another very important research stream is considering the decision-making as an argumentation process in order to integrate and support conflict prevention. Karacapidilis and Papadis (Karacapilidis \& Papadias, 2001) consider collaborative decision-making to be a process of "collaboratively considering alternative understandings of the problem, competing interests, priorities and constraints". Their research work towards the definition of Collaborative Decision Support Systems (CDSS) is based upon the definition of Kreamer (Kreamer \& King, 1988). Karakapidilis and Papadias (Karacapilidis \& Papadias, 2001) develop the "Hermes" system to support collaborative decision-making. They define this system as a "generic active system that efficiently captures users' rationale, stimulates knowledge elicitation and argumentation on the issues under consideration, while it constantly (and automatically) checks for inconsistencies among users preferences and considers the whole set of the argumentation items asserted to update the discourse status".

Munkvold (Munkvold, Eim, \& Husby, 2005) focuses on collaborative IS decision-making processes: "complex decision-making processes, involving multiple stakeholder groups". This research work concerns the specification, selection and acquisition of a new IT solution for collaboration and information management. The authors consider this process to be a collaborative decision-making process. One of the points underlined by the research study is also identification of potential challenges when using different collaborative technologies in the decision-making process: : 1 ) ensuring the continuity in the project; 2 ) ensuring effective 
communication among different stakeholder groups and 3) gaining involvement and commitment from the business areas.

In order to build a decision support system, Hamel (Hamel, Pinson, \& Picard, 2005) underlines the need to explicitly model behaviour including the interactions as well as the actions of the actors. The authors propose the use of a Multi-Agent Based Simulation (MABS) in order to take into account the interactions between individuals. This is because MABS has the ability to cope with simple entities as well as the organisations and interactions between entities and groups. The ACKA model that is proposed is based upon two principles: the definition of modelling and conceptual roles and a definition of the decision-making process as a series of interactions between stakeholders.

As for the engineering design fields, the definition as well as the specificities of the collaborative decision-making are a consequence of the definition of the collaboration process and integration of systems engineering tools in the design (Browning, 2002; Lindemann, Maurer, \& Braun, 2008; Wyatt, Eckert, \& Clarkson, 2009) The collaborative decision-support tools are mostly oriented towards obtaining a reasonable trade-offs in the design process (Holley, Yannou, \& Jankovic, 2010) integrating tools like DSM (design structure matrices) based tools.

\section{Collaborative deCISION-MAKING IN VEHICLE DEVELOPMENT PROJECTS}

This first study concerns the collaborative decision-making in early stages of the vehicle development process (Jankovic, 2006; Jankovic, Stal Le Cardinal, \& Bocquet, 2009). The proposed model to support the design process concerns two major aims: 1) identifying key parameters for collaborative decision making in order to support the design team and 2) proposing an adequate support tool integrated into project management tools. The developed model is a base for project design support tool already discussed in previous work of authors (Jankovic, Stal Le Cardinal, \& Bocquet, 2009).

\subsection{Industrial Context: Project Definition Phase}

The New Product and Process Development (NPPD) is one of the key processes contributing to the enterprise success and future development (Marxt \& Hacklin, 2004). The beginning of this process is the identification of client needs resulting from the market research. This first phase, the conceptual design phase, has a crucial importance for the overall design process. It is already widely accepted that the conceptual design process consists of generation of concepts, exploitation of these concepts and evaluation (Pahl, Beitz, \& Wallace, 1996; Ulrich \& Eppinger, 1995). The extreme importance of these stages is underlined by: 1 ) the fact that it is a value definition stage ( $80 \%$ of all life cycle costs are engaged in this stage), 2 ) the changes in this stage impacting the whole product life cycle, like manufacturing or distribution processes, and 3) the innovation which represents the added value generated and integrated within this phase. 
The Project Definition phase is at the very beginning of the conceptual design and is considered to be very complex. During this phase all aspects of one project are to be defined. Project organisation and management are set up throughout the fulfilment of functions assigned to every project team member.

The beginning of this phase is a clear definition of client's needs defined by the marketing department addressing the characteristics of the market share that is targeted. Based upon these definitions, different departments defined strategic orientations for the given development project. The involved departments are marketing, production, innovation, and strategy (see Figure 1).

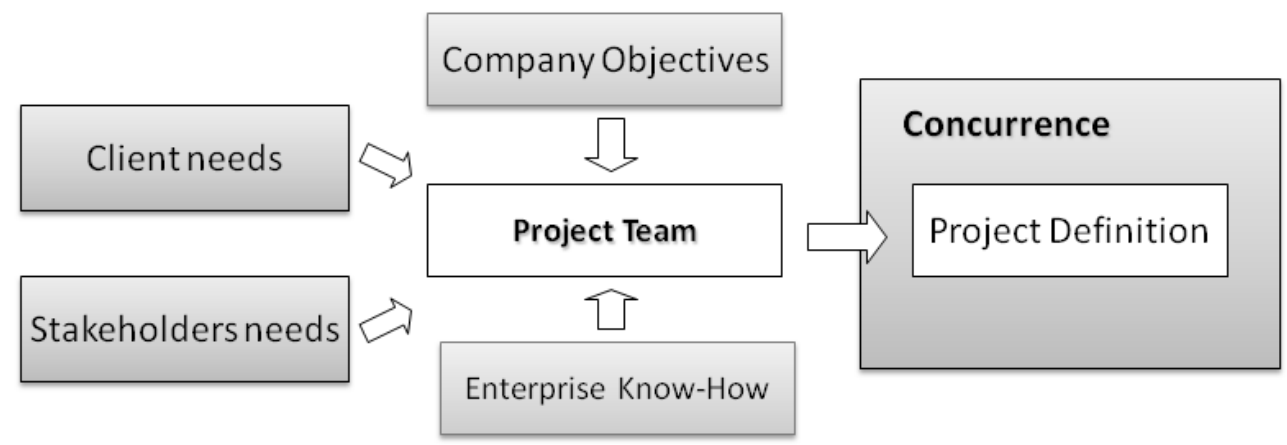

FIGURE 1. PROJECT OBJECTIVES : CONTEXT DEFINITION (JDS)

The project team's mission is to transcribe these strategic orientations onto the project objectives, to decompose them on sub-objectives and discern their global incoherence in order to propose coherent ones. In order to fulfil its mission, the project team has to collaborate with several departments that are responsible for the definition of global enterprise orientations and the ones that detain the enterprise know-how (knowledge poles). The definition of project objectives is a difficult task due to the compromise that must be found between enterprise knowledge and enterprise ambitions, i.e. strategic orientations.

Because a vehicle is a complex system, one of the difficulties of this phase is that there are more than hundred objectives to take into account on the vehicle system level. In order to consider more formal decision-support tools, in this study we have also identified different decision making objectives. More than 150 objectives were identified. The correlations between these objectives are not often determined, therefore there is no certainty about the influence that one objective could have on another. Furthermore, the Project Definition phase is crucial for the introduction of innovation. In this phase, the project team has to select the innovations that are interesting according to the type of vehicle but also feasible 
for the given time line. This innovation introduction increases the difficulty of identification of possible correlations between project objectives.

\subsection{Decision-making in the Project Definition Phase}

The Project Definition phase is also a collaborative decision-making phase. The decision makers in the Project Definition phase are experts for one aspect of the product development (motorisation, economic aspects, architecture, etc.), each of them having different information and knowledge concerning the problem (figure 2). The difficulties in collaborative decision-making in this phase come from:

1. The difficulties to asses and evaluate the uncertainties that are inherent to the early design phases,

2. The difficulties of evaluating the potential impacts of different decision-making alternatives and

3. The necessity to cascade design objectives which induces that the decision-makers have common objectives but also their own, domain specific, objectives that are often contradictory.

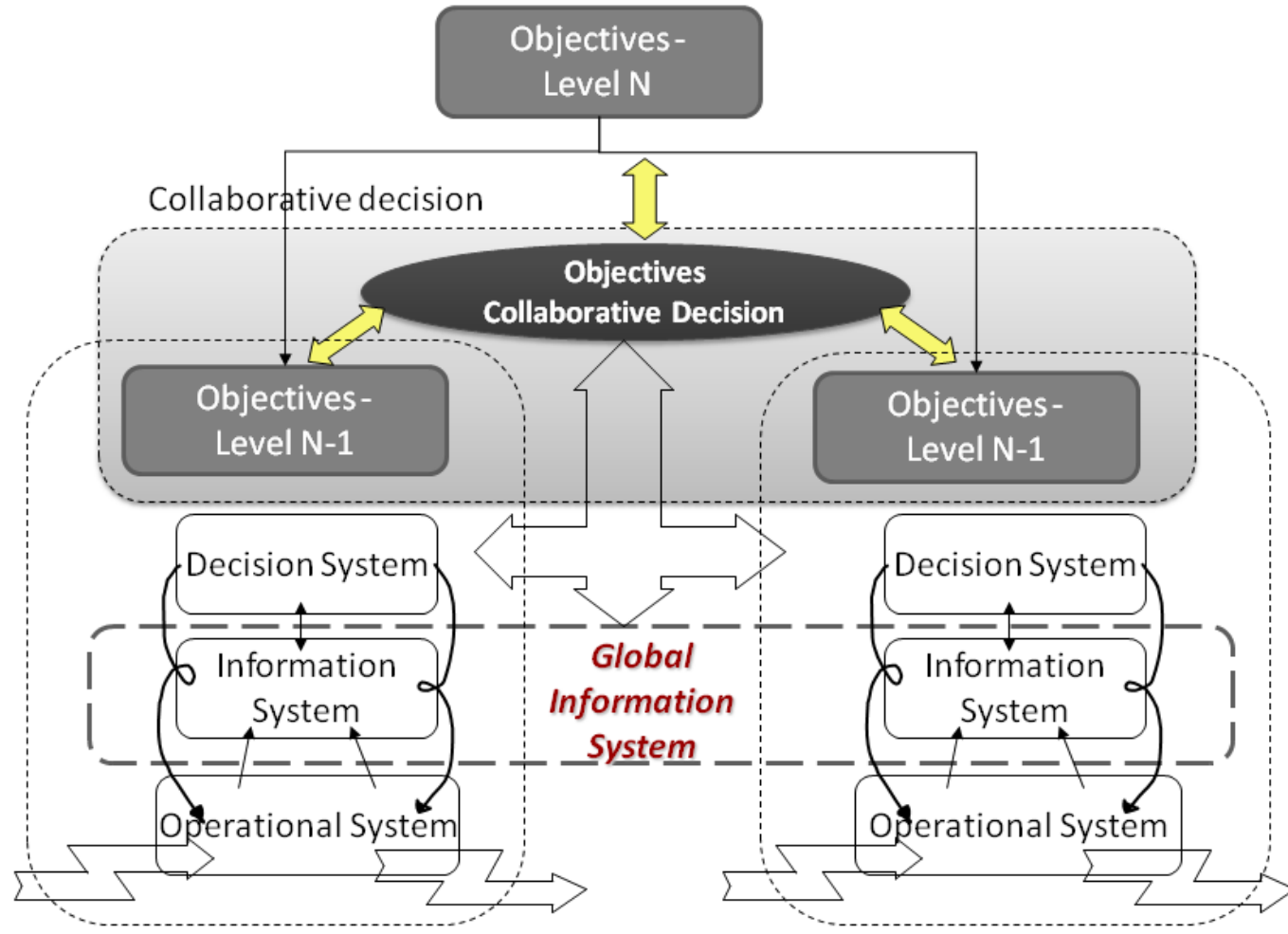

FIGURE 2. COLLABORATIVE DECISION-MAKING (THESE)

The collaborative decision-making represents a rich way for decision alternatives generation. In the design project, it is already accepted that the collaborative decision-making is creating favorable conditions for synergy development. Previous studies on collaboration processes in engineering design have already explored the benefits and difficulties in these processes (Rose, 2000). Collaborative decision-making is also a necessary approach in design projects. Development of new products demands a very large body of knowledge in different 
scientific domains and a comprehension of interactions between these domains. Therefore, it is a decision-making process that involves a large number of decision-making actors having a specific domain oriented point of view and different knowledge concerning the same problem. Moreover, due to this fact, the collaborative decision-making is considered to be a better informed process. Upper statements sustain the possibility of a better-quality decision-making process. As actors all together have knowledge in several project fields, more information and are influenced by synergy effects, the collaborative decision-making process is resulting in a bigger number of alternatives and thus a possibility of a higher quality of decision.

Nevertheless, this type of decision-making, even though showing great advantages is not without some inconveniences and problems that must be taken into account:

1. Every decision maker has preferences concerning the decision. These preferences are due to the fact that each actor has his own domain specific objectives.

2. We can see some problems of different value judgements that every decision maker has for the same decision. The decision-makers have different backgrounds and different information, and therefore have different preferences. Negotiations among themselves are then necessary.

3. The specificity of collaborative decision making process is the existence of different objectives. Every actor has specific objectives that are important to satisfy, otherwise the project has chance to be stopped.

4. As collaborative decision-making is a multi-actor process, the problem of post-control is an important issue. Development projects are situated in the dynamic environment and it is necessary to follow-up the coherence between the chosen solution(s) and developing solutions.

\section{Conceptual Model of Collaborative Decision-making}

The collaborative decision-making model is developed in order to identify key parameters in collaborative decision making and therefore identify intrinsic elements and data necessary in the process. This model is based upon the systems theory developed by Le Moigne (Le Moigne, 1990). Le Moigne defines the concept of General System as a representation of an active phenomenon comprehended as identifiable by its project in an active environment. Therefore we have developed four different points of views in our collaborative decisionmaking model: Objectives View, Process View, Transformation View and Environment View. These views are interdependent and are not to be taken separately.

The model and its implementation have already been object of publications (Jankovic, Stal Le Cardinal, \& Bocquet, 2009). Therefore, we will expose only the essential elements necessary for the understanding of the model. 
Objectives View concerns objectives in collaborative decision-making processes. This view takes into account different objectives influencing the process, as well as their relationships. The collaborative decision-making objectives are also influenced by actors' preferences.

Environment View relates to the relevant information concerning the development process, in our case the conceptual design phase, and captures the knowledge on one company. It is considered to represent the company "know-how". Three different environments influence collaborative decisions in the New Product and Process Development:

1. Decision environment,

2. Project environment,

3. Enterprise environment.

Each of these environments is identified by its context, determining the influencing factors of collaborative decision-making and different actors relevant for collaborative decisionmaking. Therefore, Decision Environment is identified by decision-making context and actors participating in the collaborative decision-making process. This environment is influenced by the Project Environment, equally defined by Project Context and Project Influence Groups. Project and Decision Environment are influenced by the Enterprise Environment, identified by its context and actors.

The Process View represents the general decision-making process proposed for the conceptual design phase. Collaborative decision-making process is a complex humaninteraction and human-cognition process. Therefore, we have identified 3 general phases of collaborative decision-making process:

1. Identification of the need for decision-making,

2. Decision-making phase,

3. Implementation and Evaluation.

In the model we underline that every process implies the utilisation of the resources, human or material. The main objective of the clearly defined collaborative decision-making process is to ensure its quality. The correlation between the formalization of the decision-making processes and its outcome has been explored and confirmed by several studies (Courtright, 1978; Kameda \& Sugimori, 1993; Neck \& Moorhead, 1995).

The Transformation View represents a dynamic view of the decision-making process. The main objective is to support information flow and changes that can be: spatial (transfer of information) or formal (transformation of the information into new information). These transformations can be grouped in two groups:

1. Preparatory transformations and

2. Implementing transformations.

Preparatory transformations represent information required in order to dispose to necessary elements for decision making. Implementing transformations represent information concerning transformation the implementation of the made decision. 


\section{A CoOperative Decision Support Framework}

Cooperative Decision Making is seen as a process and in order to support it efficiently, we propose a general framework composed by several tools.

For this kind of framework, cooperation is defined at two levels: Man/Machine cooperation and Cooperation among several decision makers.

In her work, Zaraté (Zaraté, 2005) proposes a Cooperative Decision Support framework. It is composed by several tools:

- An interpersonal communication management system,

- A task management system,

- A knowledge management tool,

- A dynamical man/machine interactions management tool.

This framework is described in the figure 4.

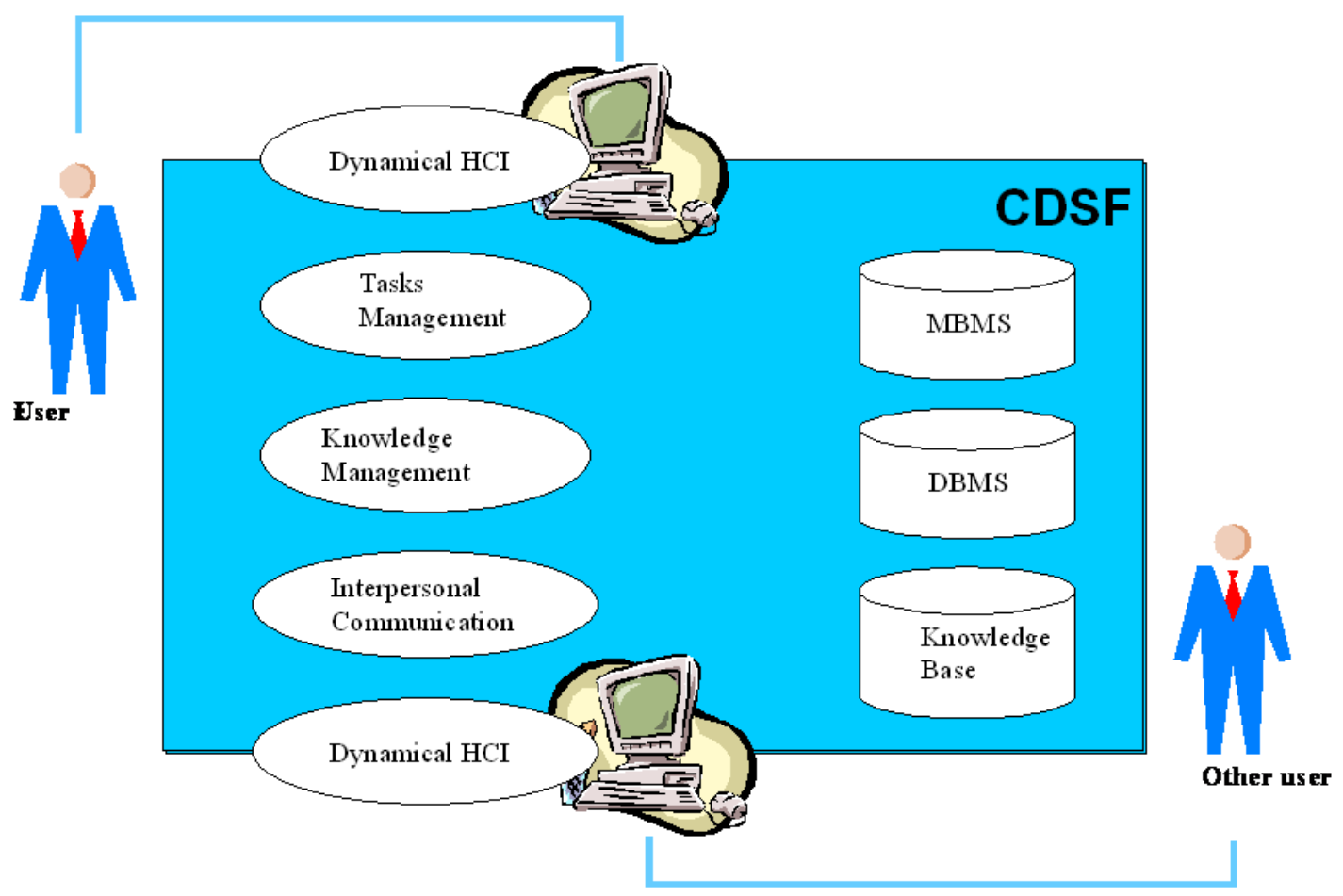

FIGURE 3. ARCHITECTURE FOR THE COOPERATIVE DECISION SUPPORT FRAMEWORK 
The interpersonal communication management tool is able as in every kind of Computer Supported Collaborative Work (CSCW) tool, to help users and decision-makers in the interactions among themselves.

The dynamical man/machine interactions management tool guides the users in their processes of solving problems in order to solve the misunderstanding problems. This package is able to avoid misunderstanding between the system and the user by proposing new solutions and is under development.

The knowledge management tool storages the previous decision made by the group or by other groups. The system proposes solutions or part of solutions to the group in very similar situations. In the case of a different situation the system must be able to propose the solution the most appropriated and the users could accept it or not. This tool is based on a knowledge management tool.

Based on the DSSs' architecture defined by Sprague and Carlson (1982), the system includes also a Data Base Management System, a Model Base Management System. Nevertheless, this system is based on the development of Knowledge Based System and more particularly Cooperative Knowledge Based System. Thus, the proposed system includes a Knowledge Base.

The task management tool is based on a Cooperative Knowledge Based System developed at the IRIT laboratory. This Cooperative Knowledge Based Architecture is developed through libraries of models: users' models, domain models (or problems models) and contextual models. The calculation of the proposed solutions is based on several techniques: planning tools (for more details see (Camilleri, 2000)), linear programming (see (Dargam, Gachet, Zaraté, \& Barnhart, 2004)). The main usage principle of this kind of tool is based on the interaction between the system and the users. The system proposes a solution to the group, the group takes in charge some tasks and then the system recalculates a new solution and proposes the new one to the group and etc. The problem or the decision to made is solved steps by steps each actors (system and users) solving parts of the problem (for more details on this tool see Camilleri, Soubie and Zaraté 2008).

This tool has for objective to propose solutions or part of solutions to users. It calculates the scheduling of tasks and sub-tasks and each role that are assigned to each tasks. It also proposes an assignment of tasks to users or to the system itself.

The main idea of this work is to find complementary aspects of the conceptual model and the Collaborative Decision Support Framework.

\section{Complementary Study of the Model and the Collaborative Decision Support FRAMEWORK}

The collaborative decision-making model represented using the UML 2.0 modeling language is represented in the Figure 4. The main question is this comparison study is what parameter or data are supported by Cooperative Decision Support framework (CDSF) and what is to be done in order to extend this support in the conceptual design phase. In order to address 
these issues, a quick overview of different data is given as well as the possibility of their support. This is represented in the Figure 4.

The objectives view gives a global overview of the collaborative decision-making objectives and their relationships. As we already stated in the part 2 of this paper, the collaborative decisions are decisions for which actors have different operational objectives. Therefore, the class Actor is associated with the class Operational_Objective. One actor can have one or more operational objectives and one objective can concern several actors. Each actor has a role in the collaborative decision-making process, thus the Actor class has an association relationship with the class Role.

The Collaborative_Decision_Objective class represents an aggregation class of several Operational_Objective. They are defined by their name (Decision_Obj_Name), their value (Defined_Value) and the deadline for their realisation (Objective_Milestone) so that the project does not have any delay. Collaborative decision-making objectives are defined in view to satisfy different client needs identified during the NPPD. Therefore the Collaborative_Decision_Objective class has an association relationship with the class Client. The Enterprise_Goal is a link class of the relationship between the Collaborative_Decision_Objective and the Client class. As the NPPD process is a collaborative process and some objectives are given by different collaborators (like production or distribution), the class Actor represents an inheritance class of the class Client.

The attributes of the Collaborative_Decision_Making_Process are Name, the Decision_Importance and the Decision_Making_Phase. This class is composed by Ressources class, itself composed of Material_Resources and Human Resources classes. The Human_ressources is a generalised class of the Actor class. The Actor class has a directed association relationship with the Collaborative_Decision_Making class named "participates in". 


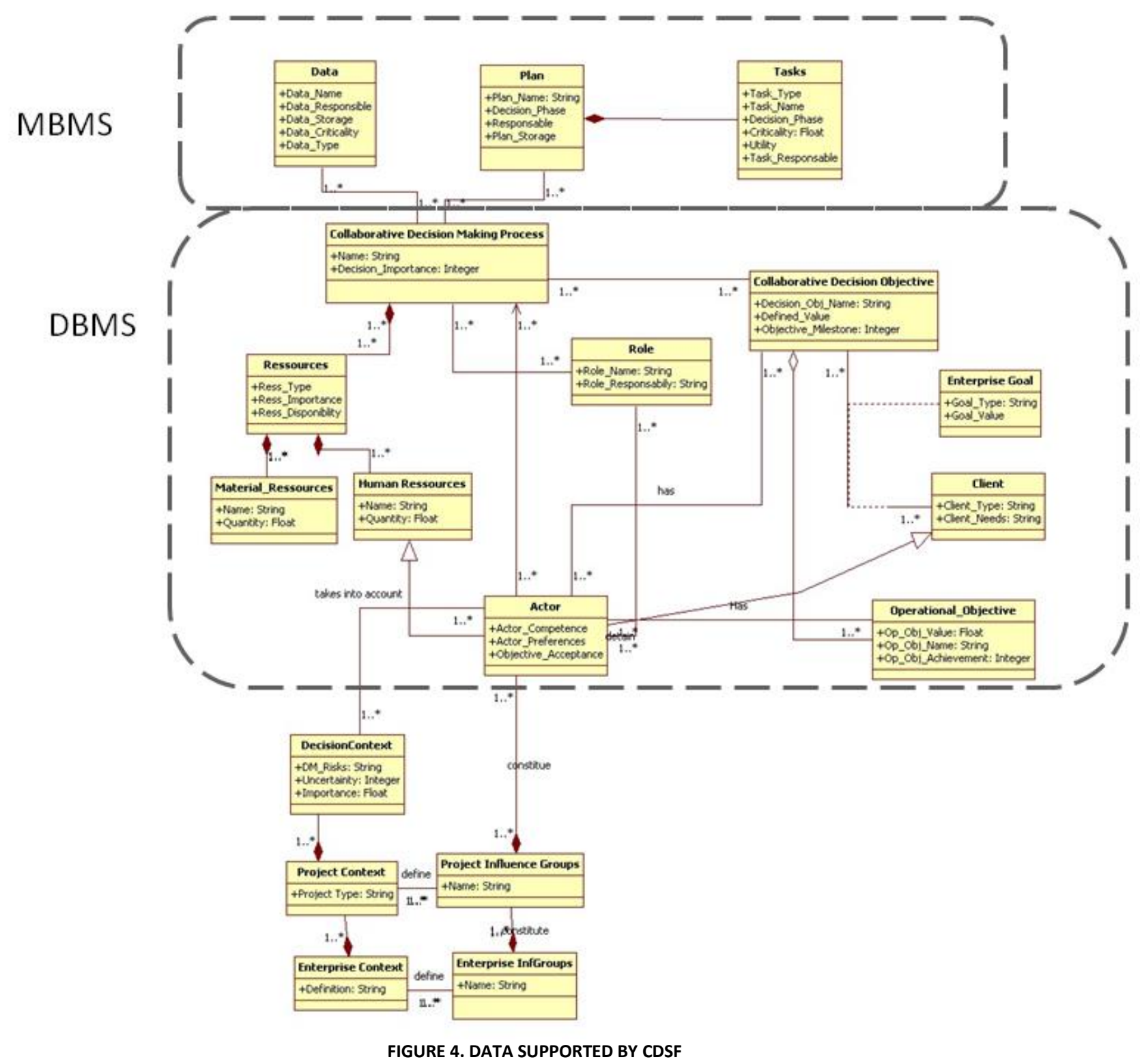

The Collaborative_Decision_Making_Process class has an association relationship with the Data and the Plan class. The Plan class is composed of different activities represented with the Tasks class. The Data class is defined by several attributes: Data_Name, Data_Responsible - the person qualified to give such an information, Data_Type - if the data is used in the preparation for the decision or in the implementation phase, Data_Storage the place where this data can be found and Data_Criticity - the probability of obtaining the data on time for the decision. The Plan class has Plan_Name, Plan_Type - preparatory or implementing plan, Responsible and Plan_Storage - indication of the place where the given plan can be found. The Plan class is a parent class for the Task class (Task_Type, Task_Name, Criticality, Task_Responsible).

Both Objectives and Transformations Views of the model are easily supported by Data Base management system. It is also interesting that the part concerning the design objectives in engineering studies is mostly oriented towards an expert-based systems or rule-based systems supporting the decision in design. Therefore, it might be interesting to combine 
theses two approaches in order to have a more efficient system addressing both points of views: decision and design.

Environment view is only partially presented because this view concerns the knowledge of the collaborative decision-making process as well as the new product development process. This view represents the "know-how" of the organization addressing the issues of project organization, communication channels, and enterprise decision-making process. As it is the "know-how" it is very difficult to present it using the UML modeling language. Therefore, it may be useful to consider other languages for it representation. Nevertheless we consider possible to develop the Knowledge Base system supporting this kind of problems in the collaborative decision-making process.

In short the information presented in the class diagram of the collaborative decision-making process we can identify different parts of the CDSF supporting the given information: information contained in the Transformations view can be supported by the Model Base Management System, Objectives and Collaborative Decision Making Process by the Data Base Management System and the Environment view by the Knowledge Base. The corresponding schema is given on the figure 6 .

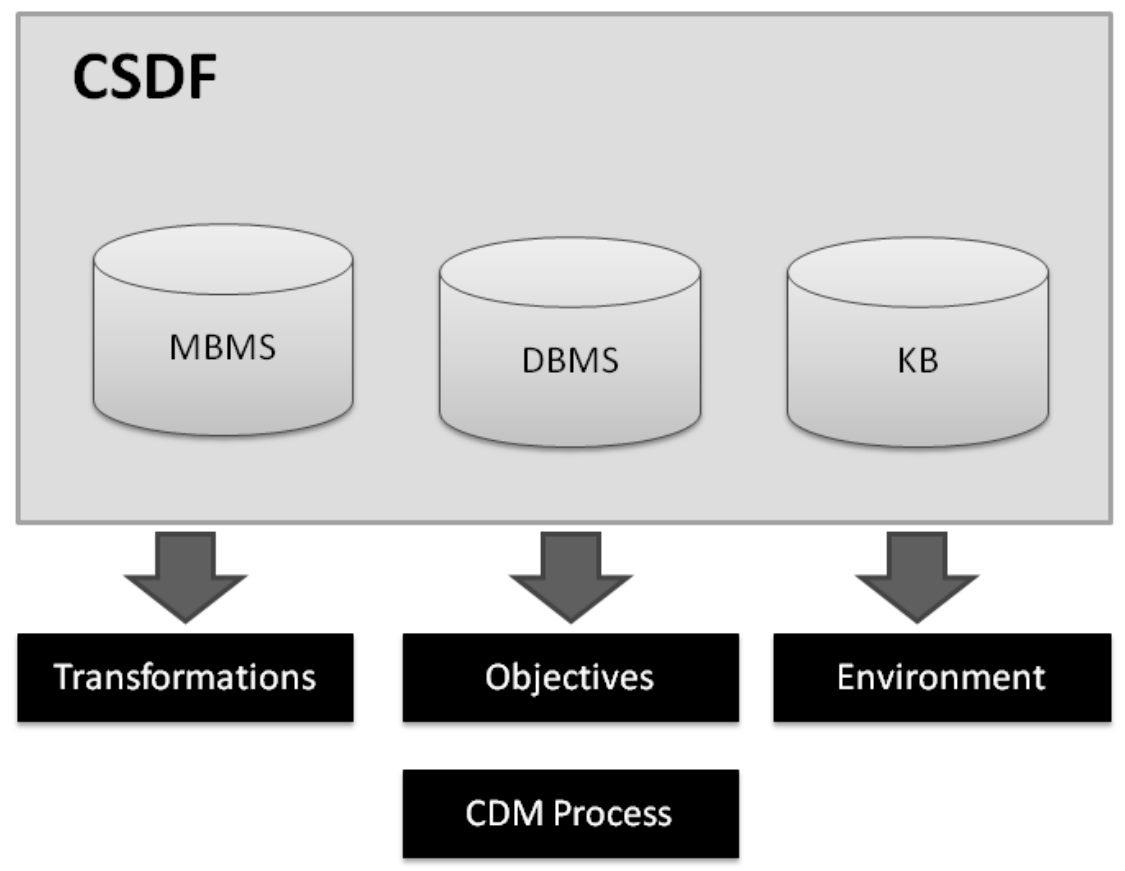

FIGURE 5. CDSF SUPPORT FOR COLLABORATIVE DECISION MAKING IN ENGINEERING DESIGN

The information concerning the Objectives view and the Process view can be supported by the Data Base Management System (DBMS). This system contains all information concerning 
collaborative decision-making objectives, different actors participating and their roles in the decision-making process, different activities in the decision-making, as well as necessary resources for the decision. The Model Base Management System (MBMS) contains different model at the decision-makers' disposal. Therefore it can support the Transformations View, addressing the issue of different plans and the tasks before and after the collaborative decision-making. The models can be proposed regarding the operational needs of one project team.

\section{CONCLUSIONS}

Artificial Intelligence and engineering design have different definitions and considerations concerning the cooperative and collaborative decision making. Whilst for Al the most integrated approach in term of sharing the decision-making objectives is cooperative decision-making, for engineering design field it is the collaborative decision-making due to the particularity of the product development process. Moreover, the characteristics of cooperative and collaborative decision-making are not the same in these two fields.

Two research studies have been taken into account: one concerning the collaborative decision-making in early design stages in vehicle development and the second one concerning the proposition of the general Cooperative Decision Support framework. Main objective of this research work is to identify the discrepancies and analogies in addressing the decision-support concerning the two proposed research studies. Therefore, the authors try to address: 1) key parameters or data that are indentified and supported by both approaches and 2) differentiating elements with the aim of discussing potential further developments concerning decision-support tools.

The comparison of this model and CSDF has pointed out that the information contained in the Objectives and Process view can be supported by Data Base Management System (DBMS). The Transformations view can be supported by different model at the decisionmakers' disposal in the Model Base Management System (MBMS). As for the Environment view, even though this part is only partially captured in this model and corresponds to the know-how, we consider to be possible to develop a Knowledge Management (KM) database in order to organise and capitalise the knowledge. The class diagram formalism has been used in order to structure the Data Base, the Model Base and the Knowledge of the Collaborative Decision Support Framework.

The authors can retrieve several conclusions from this comparative study. Firstly, the information identified for the collaborative decision-making support can be entirely supported by the CSDF. We also show that the type of information classified in different views of the model correspond to well identified parts of the framework. Secondly, we can conclude the possibility to apply the CSDF during the project management in the Project Definition phase. Nevertheless, some issues have to be dealt with: the cost of such a platform and ergonomic aspect that are user oriented. Moreover, it seems interesting to integrate some of the expert-based systems or rule-base systems that address the collaborative decision-making support in design. Thirdly, even though the collaborative 
decision-making model was developed for the purpose of project management, the construction of the model with the types of information identified in the case of collaborative decision-making support can be generalised to other decision contexts and situation.

\section{REFERENCES}

Aldunate, R., Pena-Mora, F., \& Robinson, G. (2005). Collaborative distributed decision making for large scale disaster relief operations: Drawing analogies from robust natural systems. COMPLEXITY, 11(2), 28-38.

Browning, T. R. E., S.D.; . (2002). Modeling impacts of process architecture on cost and schedule risk in product development. EEE Transactions on Engineering Management, 49(4), 428 - 442

Camilleri, G. (2000). Une approche, basée sur les plans, de la communication dans les systèmes à base de connaissances coopératif. Université Paul Sabatier, Toulouse.

Chim, M. Y., Anumba, C. J., \& Carrillo, P. M. (2004). Internet-based collaborative decision-making system for construction. Advances in Engineering Software, 35(6), 357-371.

Cil, I., Alpturk, O., \& Yazgan, H. R. (2005). A new collaborative system framework based on a multiple perspective approach: InteliTeam. Decision Support Systems

Collaborative Work and Knowledge Management, 39(4), 619-641.

Courtright, J. A. (1978). A Laboratory Investigation of Groupthink. Communication Monographs, 45(3), 229-246.

Dargam, F., Gachet, A., Zaraté, P., \& Barnhart, T. (2004). DSSs for Planning Distance Education: A case Study. In Decision support in an uncertain and complex world (pp. 169-179). Prato: Meredith R., Shanks G., Arnott D., Carlsson S.

Hamel, A., Pinson, S., \& Picard, M. (2005, September 19-22). A new approach to agency in a collaborative decision- making process. Paper presented at the International Conference on Intelligent Agent Technology.

Holley, V., Yannou, B., \& Jankovic, M. (2010). Using Quality Function Deployment (QFD) to bring design department voice in the choice of concepts. Paper presented at the The 12th International DSM Conference, Cambridge, United Kingdom.

Jankovic, M. (2006). Collaborative decision making in new product development. Application to the car industry. Unpublished PhD Thesis, Ecole Centrale Paris, Paris.

Jankovic, M., Bocquet, J.-C., Stal Le Cardinal, J., \& Bavoux, J.-M. (2006, May 15 - 18, 2006). Integral Collaborative Decision Model in order to Support Project Definition Phase Management. Paper presented at the International Design Conference - Design 2006, Dubrovnik, Croatia.

Jankovic, M., Stal Le Cardinal, J., \& Bocquet, J.-C. (2009). Collaborative Decision in Design Project Management. A Particular Focus on Automotive Industry. Journal of Decision Systems.

Kameda, T., \& Sugimori, S. (1993). Psychological entrapment in group decision making : an assigned decision rule and a groupthink phenomenon. Journal of personality and social psychology, 65(2), 282-292.

Karacapilidis, N., \& Papadias, D. (2001). Computer supported argumentation and collaborative decision making: the HERMES system. Information Systems, 26(4), 259-277.

Kim, S.-y., Godbole, A., Huang, R., Panchadhar, R., \& W., S. W. (2004). Toward an integrated human-centered knowledge- based collaborative decision making system. Paper presented at the IEEE INTERNATIONAL CONFERENCE ON INFORMATION REUSE AND INTEGRATION.

Kreamer, K. L., \& King, J. L. (1988). Computer-based systems for cooperative work and group decision making. ACM Computing surveys, 20(2), 115-146.

Le Moigne, J.-L. (1990). La modélisation des systèmes Complexes. Paris: Dunod.

Lindemann, U., Maurer, M., \& Braun, T. (2008). Structural Complexity Management. An Approach for the Field of Product Design. Berlin Heidelberg: Springer-Verlag. 
Marxt, C., \& Hacklin, F. (2004, May 18-21). Design, Product Development, Innovation: All the same in the End? A Short Discussion on Terminology. Paper presented at the International Design Conference - Design 2004, Dubrovnik.

Munkvold, B., Eim, K., \& Husby, O. (2005). Collaborative IS decision- making: Analyzing decision process characteristics and technology support. LECTURE NOTES IN COMPUTER SCIENCE, 3706, 292- 307.

Neck, C. P., \& Moorhead, G. (1995). Groupthink Remodeled: The Importance of Leadership, Time Pressure, and Methodical Decision-Making Procedures. Human Relations, 48(5), 537-557.

Pahl, G., Beitz, W., \& Wallace, K. (1996). Engineering design: a systematic approach. London, UK: SpringerVerlag.

Panzarasa, P., Jennings, N. R., \& Norman, T. J. (2002). Formalizing collaborative decision-making and practical reasoning in multi-agent systems. Journal of Logic and Computation, 12(1), 55-117.

Rose, B. (2000). Proposition d'un référentiel support à la conception collaborative : CO²MED (COllaborative COnflict Management in Engineering Design), Prototype logiciel dans le cadre du projet IPPOP. Unpublished PhD Thesis, U.F.R. Sciences et Techniques Mathématiques, Informatique et Automatique.

Shim, J. P., Warkentin, M., Courtney, J. F., Power, D. J., Sharda, R., \& Carlsson, C. (2002). Past, present, and future of decision support technology. Decision Support Systems, 33(2), 111-126.

Ulrich, K. T., \& Eppinger, S. D. (1995). Product Design and Development. New York: Irwin McGraw-Hill.

Wyatt, D. F., Eckert, C. M., \& Clarkson, P. J. (2009, August 24-27). Design of product architectures in incrementally developed complex products. Paper presented at the 17th International Conference on Engineering Design' ICED'09, Stanford, California, U.S.A.

Zaraté, P. (2005). Des Systèmes Interactifs d'Aide à la Décision aux Systèmes Coopératifs d'Aide à la Décision. Unpublished Habilitation à Diriger des Recherches, Institut National Polytechnique de Toulouse, Toulouse. 